\title{
A informação social no corpo travesti (Belém, Pará): uma análise sob a perspectiva de Erving Goffman
}

\author{
Rubens da Silva Ferreira \\ Professor da Faculdade de Biblioteconomia do Instituto de Ciências Sociais Aplicadas da UFPA. M.Sc. Planejamento do Desenvolvimento \\ (NAEA/UFPA). Esp. em Biblioteca Universitária (CSE/UFPA). \\ E-mail: rubenspa@yahoo.com
}

\section{Resumo \\ Inspiradas em um ideal de mulher, as travestis investem em uma morfologia híbrida, combinando signos de masculinidade e feminilidade, que acabam por desqualificá-las para a sociedade maior. Partindo da noção de informação social de Goffman, este trabalho tem por objetivo fazer uma leitura dos corpos dos sujeitos em questão, o que se dá sob uma perspectiva relacional. O corpus submetido à análise constitui-se do material obtido de pesquisa etnográfica realizada em 2002 e 2003 entre as travestis que se prostituem em Belém, Pará. De modo geral, os corpos das travestis comunicam uma diversidade de informações, as quais falam sobre estigma, desvio, violência e desejo na capital paraense.}

\section{Palavras-chave}

Ciência da informação. Informação social. Gênero. Travestis. Belém.

\section{Social information in the travesty corpus (Belém, Pará): an analysis of Erving Goffman's point of view}

\begin{abstract}
Having in mind a woman ideal, the travesties make use of a hybrid morphology, matching signs of masculinity and femininity, but the result is that they disqualified for a major society. This way, based on the notion of Goffman's social information, the objective of this paper is to analyze the bodies of the referred individuals, what is carried out according to a relational perspective. The corpus under analysis is the material obtained from an ethnographic research carried out in 2002 and 2003 among travesties, prostituted in Belém, Pará State. In general, the bodies of travesties show forth a diversity of information which conveys stigma, deviation, violence and wish, in the State capital.
\end{abstract}

\section{Keywords}

Information Science. Social information. Sex. Travesties. Belém. 


\section{INTRODUÇÃO}

A interdisciplinaridade da ciência da informação emana de seu próprio objeto, que ao estar visceralmente associado aos diferentes domínios da vida ${ }^{1}$ passa a exigir abordagens complexas, demandando debates, estudos e experimentos metodológicos envolvendo diversas disciplinas em direção ao entendimento da informação. Em face dessa constatação, o que se busca neste artigo é realizar um exercício de interseção entre a ciência da informação e a antropologia, a fim de evidenciar um campo de possibilidades de análise para além das novas tecnologias de comunicação e informação (NTCI), as quais têm sido demasiadamente estudadas pela academia.

O elemento condutor deste exercício é o que Erving Goffman (2008; 2005) chama de informação social. Conforme o autor, essa modalidade de informação corresponde ao conjunto de signos verbais e nãoverbais comunicados acidental ou intencionalmente, total ou parcialmente nas interações entre os indivíduos. Fundamentalmente ela representa aquilo que o indivíduo expressa de si e impressiona o outro (GOFFMAN, 2005). Ao considerar a dinâmica desse processo comunicativo muito presente na vida cotidiana, envolvendo essencialmente informações não estruturadas, tal exercício se dá a partir das observações das interações entre travestis e não travestis na cidade de Belém, no estado do Pará, orientando-se pela questão: o que o corpo andrógino das travestis ${ }^{2}$ comunica para a sociedade maior?

\footnotetext{
${ }^{1}$ Aqui se faz referência à troca de informação em uma dimensão mais ampla, envolvendo diferentes seres vivos, sejam humanos ou não. No último caso, estudos sobre a comunicação entre mamíferos, aves e répteis dão conta de que os sinais articulados entre animais como os que indicam marcação de território, submissão e propensão à corte etc. - são dotados de sentido e considerados pelos biólogos como informações transmitidas entre os mesmos (QUEIROZ, 2006), estando fundamentalmente associadas à sobrevivência das espécies. ${ }^{2} \mathrm{O}$ emprego do artigo feminino precedendo o termo travesti (s) foi determinado não apenas porque esses sujeitos têm reivindicado o tratamento na forma feminina (MOTT, 2000; FERREIRA, 2003a), mas porque os processos comunicativos entre si, com clientes, amigos e familiares se dão predominantemente através de classes gramaticais desse gênero, consistindo, portanto, num traço peculiar dessa subcultura homossexual.
}

A condução metodológica do trabalho foi orientada pela pesquisa etnográfica conforme as orientações de Malinowski (1989), Oliveira (1996) e Simonian (2000), sobretudo no que diz respeito à identidade dos (as) informantes e no registro do que era ouvido, sentido e fotografado durante o trabalho de campo. A coleta de evidências foi realizada com base em entrevistas e observações conduzidas nos dois territórios de prostituição de travestis conhecidos em Belém: o bairro do Marco e do Reduto. Enquanto no primeiro pode ser encontrado um pequeno grupo de 13 de indivíduos distribuídos ao longo das transversais da Av. Almirante Barroso, no segundo tem-se cerca de 40 sujeitos trabalhando nas transversais da Av. Assis de Vasconcelos. Nas estadas em campo foram entrevistadas 22 travestis, uma delegada e 18 moradores, sendo que as vozes desses últimos foram importantes no sentido de entender a leitura que fazem dessa realidade, ainda que muitos tenham se reservado o direito de permanecer em silêncio, segundo eles, por uma questão de "segurança".

O trabalho de campo compreendeu o período entre abril e outubro de 2002 e março de 2003, por ocasião da elaboração da dissertação de mestrado apresentada ao Núcleo de Altos Estudos Amazônicos (NAEA/UFPA). Desse modo, o que se socializa neste momento é uma análise sobre o "excedente empírico" resultante das idas ao campo. Ou seja, o produto das observações intensivas, registradas nas margens do diário e que não foi incorporado à dissertação, todavia merecendo uma abordagem analítica posterior, o que se faz neste artigo à luz do debate entre a antropologia e a ciência da informação.

Tratadas essas considerações preliminares, segue uma discussão teórica para o entendimento da informação social e das travestis. Posteriormente são apresentados os apontamentos observados no real concreto, evidenciando os muitos aspectos do que os corpos dos sujeitos em questão comunicam à sociedade maior, bem como o que ela interpreta sobre o modo de ser das travestis. Ao final, apontase que, de modo geral, as travestis comunicam não 
apenas sensualidade a partir de seus corpos marcados pela ambiguidade, como também transmitem uma imagem de sujeitos perigosos, o que se dá como estratégia de sobrevivência. Em contrapartida, a sociedade maior as interpreta de maneira ainda muito controversa, variando entre a aceitação e a intolerância, ou entre o desejo e o ódio, tal como se pode constatar a seguir.

\section{INFORMAÇÃO SOCIAL E TRAVESTIS NUMA PERSPECTIVA TEÓRICA}

A natureza interdisciplinar da ciência da informação permite que a informação - enquanto objeto de investigação - seja analisada em seus processos sociais de produção, disseminação e uso sob as diferentes matrizes do pensamento científico. Ao inscrever a informação no contexto social, ou seja, como produção humana de valor agregado pelo potencial cognitivo e (re) criativo do homem, as disciplinas estruturantes das ciências sociais podem fornecer olhares muito particulares de sua aplicação na vida diária, embora autores como Belkin (1978 apud PINHEIRO; LOUREIRO, 1995) prefiram restringir as abordagens investigativas à dimensão científica e tecnológica. Todavia, a trajetória da pesquisa em ciência da informação no Brasil tem apontado, a partir da primeira década do século XXI, para uma reorientação em direção às questões sociais. Por conseguinte, problemas como exclusão informacional, analfabetismo digital e cidadania (ARAÚJO, 1999; FERREIRA, 2003b; MATTOS, 2006; SOUSA, 2006), por exemplo, já têm emergido nos debates acadêmicos, sobretudo em função de uma massa crítica consciente de que as inovações tecnológicas nos países em desenvolvimento não têm conseguido resolver o aprofundamento das desigualdades sociais.

No caso particular da antropologia como ciência dedicada ao estudo do homem em sua dimensão cultural, há que se observar a relevância do instrumental teórico e metodológico para interpretar a informação nas microestruturas das diferentes sociedades, quais sejam aquelas classificadas como simples ou complexas. Neste sentido, Araújo (2003) traz importante contribuição ao colocar a tradição do pensamento sociológico como aspecto inerente à interpretação e ao entendimento do fenômeno social da informação. $\mathrm{O}$ autor registra o legado da Escola de Chicago sobre os processos de interação social, nos quais não se pode deixar de lado as relações de troca de informações que Goffman (2008; 2005) analisou sob o prisma da representação teatral entre indivíduos limitados pelo ambiente físico do contexto de trabalho. Como o próprio Goffman esclarece, a trama das interações sociais com trocas de informações entre os sujeitos pode ser aplicada a quaisquer outras situações da vida cotidiana.

Ao se pensar a informação social na ótica do que Belkin (1978 apud PINHEIRO; LOUREIRO, 1995) vislumbra como outro gênero de informação, importa entendê-la como categoria de análise. Quer dizer, como um conceito cujo campo semântico no contexto da produção científica ajusta-se ao olhar de cada disciplina, ganhando particularidades em razão de sua aplicação teórica. Logo, informação científica e tecnológica, informação para negócios, informação genética, informação pública, informação para cidadania, informação ambiental e informação social são modos de explicar o fenômeno da informação em determinados panoramas comunicativos, em que pese a carência de uma crítica mais acurada na literatura especializada. Ademais, tal como posto por Pinheiro e Loureiro (1995), o termo informação possui uma amplitude semântica emblemática que imprime a dificuldade de uma definição unívoca ${ }^{3}$ para as diferentes áreas do conhecimento. 
Entre as proposições encontradas na literatura, faz-se a opção pelo entendimento de Belkin e Robertson (1976 apud FREIRE, 2001), segundo os quais informação pode ser considerada como o elemento transformador de estruturas. Aliás, tal definição se aplica bem ao caso das travestis, as quais são capazes de transformar a morfologia corporal à medida que passam a integrar uma rede de relações socais em que são disseminadas informações sobre como, onde e por quanto podem obter contornos corporais mais femininos. Acrescentem-se, ainda, as informações relacionadas ao aprendizado das técnicas corporais comuns às mulheres (MAUSS, 2003), tais como o gestual com as mãos, a maneira de caminhar, de arrumar os cabelos, de vestir-se, de maquilar-se etc.

Note-se que o recurso a substâncias químicas na forma de hormônios sintéticos permite às travestis se apropriar do conhecimento médico para a consecução do projeto de ajuste corporal à identidade de gênero (OLIVEIRA, 1994; KULICK, 1998; BENEDETTI, 2000, 2005; FERREIRA, 2003a), a exemplo da experiência de Sabrina (C.M.S.; 22 anos; entrevista, 2002), que diz ter ingerido hormônios desde a adolescência, o que resultou no corpo e na voz incapazes de revelar o seu sexo.

Por meio das interações sociais com outras travestis, namorados ou clientes, os iniciantes conseguem ter acesso às informações que irão auxiliálos no investimento necessário ao aperfeiçoamento corporal. Como observou Benedetti (2000), a transformação do corpo é um processo inerente à construção da identidade desse segmento social. Ele é o marco fundamental que permite diferenciá-los de outros indivíduos que compõem a diversidade do universo sexual, notadamente no que se refere aos gays, aos transformistas, às drag queens e às cross-dressers (CDs), ou ainda, distingui-los entre as transexuais.

Como as próprias travestis costumam explicar, ser travesti é apresentar-se socialmente como mulher em tempo integral, ou como elas costumam dizer, "[...] travesti é quem passa 24 horas por dia como mulher $[\ldots]$ ". 4 . E nessa representação não basta somente vestir-se com roupas do universo feminino. A passagem de um indivíduo para o que se poderia chamar de um ethos travesti envolve cuidados constantes, tais como depilação, ingestão e/ou aplicação de hormônios sintéticos femininos ou até mesmo intervenções mais agressivas, como o uso de silicone para modelar seios, nádegas e quadris. Em alguns casos tem sido registrada a prática de medicina ilegal, de maneira que travestis conhecidas como "bombadeiras" realizam a aplicação de silicone tóxico no corpo de suas clientes (KULICK, 1998; BENEDETTI, 2000, 2005; FERREIRA, 2003a), embora estejam informadas sobre os riscos e os danos desse tipo de procedimento.

Mas todo o investimento no corpo não se dá sem consequências. Participando de uma sociedade patriarcal em que os valores e os papéis sociosexuais estão historicamente bem definidos para homens e para mulheres, o corpo andrógino das travestis passa a constituir fonte de preconceito, com efeito direto sobre a cidadania desse segmento (FERREIRA, 2003a). Desse modo, a inserção no mercado de trabalho se dá de maneira precária, uma vez que lhes são relegadas colocações estereotipadas, sendo as mais frequentes nos ramos da estética, da gastronomia e do entretenimento. Para aquelas provenientes de famílias mais pobres, a prostituição se coloca como uma das poucas alternativas de geração de renda, se não a mais recorrente.

\footnotetext{
${ }^{4}$ Indivíduos gays possuem aparência masculina e vestem-se como tais, embora possam apresentar comportamento masculinizado ou afeminado. Transformistas, drag queens e CDs não transformam o corpo, eles utilizam somente artifícios temporários (perucas, esponjas, cílios e seios postiços etc.) para simular a imagem feminina, sendo que os primeiros usam do simulacro para performances artísticas como meio de geração de renda. As transexuais, por sua vez, não apenas modificam o corpo, como almejam a intervenção cirúrgica para remover a genitália que lhes causa transtornos psicológicos, afetivos e sexuais, pois diferentemente das travestis, para esta categoria o pênis não satisfaz nenhuma funcionalidade sexual (FERREIRA, 2003a).
} 
Diante desse contexto, as travestis são duplamente discriminados, seja por violarem o sistema de sexo e gênero, seja por se prostituírem nas áreas nobres ou depreciadas dos grandes centros urbanos, como os bairros do Marco e do Reduto, em Belém. É nas ruas que eles interagem com outros travestis, clientes, moradores dos territórios de prostituição e policiais, com quem estabelecem uma forma de comunicação mediada pelo corpo, e nesse processo de interação social efetiva-se a prática de troca do que Goffman (2005) denomina informação social. Como ele explica:

Quando um indivíduo chega à presença de outros, estes, geralmente, procuram obter informações a seu respeito ou trazem à baila a que já possuem. Estarão interessados na situação sócio-econômica geral, no que pensa de si mesmo, na atitude a respeito deles, capacidade, confiança que merece, etc. Embora algumas destas informações pareçam ser procuradas quase como um fim em si mesmo, há comumente razões bens práticas para obtê-las.

Ainformação a respeito do indivíduo serve para definir a situação, tornando os outros capazes de conhecer antecipadamente o que ele esperará deles e o que dele podem esperar [grifo meu]. Assim informados, saberão qual a melhor maneira de agir para dele obter uma resposta desejada (GOFFMAN, 2005, p. 11).

Como se pode observar, essa troca de informações seve para que um indivíduo expresse as impressões que pretende causar no outro, assim como aquelas que o outro formará sobre ele.

Para definir a informação social em termos práticos, Goffman (2008, p. 52, 53) deixa claro que se trata de:

[...] uma informação sobre um indivíduo, sobre suas características mais ou menos permanentes, em oposição a estados de espírito, sentimentos ou intenções que ele poderia ter num certo momento. Essa informação, assim como o signo que a transmite, é reflexiva e corporeificada [grifo meu], ou seja, é transmitida pela própria pessoa a quem se refere, através da expressão corporal na presença imediata daqueles que a recebem.

Sendo o corpo para as travestis um aspecto chave do processo de identificação de gênero, e como esse corpo modificado desafia a condição biológica que as associa ao universo masculino, tem-se uma fonte capaz de transmitir uma diversidade de informações para a sociedade maior.

Muitas são as fontes transmissoras da informação social, sendo a mais relevante o próprio sujeito, que por meio de expressões corporais, atitudes, modo de vestir e pela aparência física está a falar de si (GOFFMAN, 2005; 2008) mesmo que de maneira imperceptível. Evidentemente todo o processo de interação social é em si um processo comunicativo, permeado pelas inferências que os atores sociais podem fazer através do que lhes é informado, pois:

É também sumamente importante que compreendamos que, na verdade, na existência quotidiana não dirigimos nossas vidas, tomamos nossas decisões ou alcançamos metas, nem de maneira estatística nem de maneira científica [grifo meu]. Vivemos de inferências. Suponhamos que eu seja, por exemplo, hóspede. O senhor não sabe, nem pode determinar cientificamente se vou roubar seu dinheiro ou seus talheres. Mas, por inferência [ou seja, pela interpretação dos meus sinais corporais e comportamentais, o senhor acredita que] não farei tais coisas, e, por inferência, o senhor me receberá como hóspede (VOLKART, 1951, apud GOFFMAN, 2005, p. 13).

O exemplo anterior ilustra bem como se dá a troca da informação social no dia a dia. Tomando o material empírico coletado junto às travestis que se prostituem na cidade de Belém do Pará, a análise a seguir levará em conta os dois extremos dessa relação comunicativa: as informações que as travestis 
transmitem a partir dos seus corpos e as inferências que moradores dos territórios de prostituição, clientes e policiais elaboram com base nos sinais lidos sobre os sujeitos em foco.

\section{O CORPO TRAVESTI COMO FONTE DA INFORMAÇÃO SOCIAL}

Entre os muitos contextos comunicativos que envolvem a informação social depreendida dos corpos das travestis, aqui se destaca aquele que se dá no exercício da prostituição em via pública. Isto porque a prostituição opera como um agravante à condição sociodesvalorizada dos sujeitos em questão. Ao recorrer a essa forma de geração de renda, as travestis se relacionam com outros indivíduos, quais sejam clientes, moradores dos territórios de prostituição, passantes, policiais, agressores e mesmo outros travestis que numa perspectiva relacional comunicam sobre si a todo o momento. E esses indivíduos, por sua vez, fazem diferentes leituras sobre os corpos das travestis.

Uma contribuição teórica capaz de auxiliar os mecanismos de articulação da informação social no segmento da prostituição é dada por Girão e Lima (1999), as quais analisaram o marketing entre as travestis de Minas Gerais. Ao considerar o sexo como um serviço negociado entre quem se prostitui de um lado e o cliente do outro, os travestis precisam investir no corpo para torná-lo o mais atraente possível. Certamente, quanto mais femininas forem, maiores serão as possibilidades de um negócio bemsucedido. Daí decorre a constatação de Silva (2007), quanto aos cuidados intensos na descaracterização de uma plástica masculina e na construção de uma estética mais próxima à da mulher, o que significa remover ou descolorir pêlos, deixar os cabelos crescerem, ingerir hormônios ou implantar/injetar silicone no corpo.

Nos territórios de prostituição da Av. Almirante Barroso, no bairro do Marco, e da Av. Assis de Vasconcelos, no bairro do Reduto, foram encontradas travestis em estágios contrastantes de modificação corporal. Do conjunto de 22 entrevistadas, somente seis (06) possuíam aspectos corporais nitidamente femininos, contra 16 nos quais se sobressaíam visivelmente os traços masculinos. Suelma (25 anos), Sabrina (22 anos), Camila (26 anos), Verônica (30 anos), Nazarena e Débora ${ }^{5}$, dotadas de seios, quadris largos, nádegas proeminentes, cintura delgada, cabelos longos e gestos suavizados são as mais procuradas pelos clientes. Seus corpos reúnem signos que comunicam feminilidade e sensualidade àqueles que procuram por serviços sexuais.

O recurso a determinadas técnicas corporais e o estilo de vestir-se agregam valor às travestis que vivem da prostituição, o que as faz (re) inventar uma feminilidade quase esquecida pela imagem da mulher na modernidade, esta cada vez mais competitiva e menos romântica. Tal como analisado por Mauss (2003), as técnicas corporais correspondem ao modo como os indivíduos utilizam seus corpos na vida social, o que envolve, entre outros elementos, uma gestualidade peculiar a cada gênero. Logo, no jogo de sedução para atrair a clientela, as travestis elaboram formas de andar, de arrumar os cabelos, de movimentar as mãos e a cabeça que, combinadas ao vestuário minimalista e aderente ao corpo, permitem ao cliente escolher aquela que mais estimula a libido e a fantasia.

Ainda neste ponto, Silva (2007) ressalta a elaboração de um falar em falsete para suavizar a voz, tornando-a mais aguda, portanto, feminina. Como se pode perceber, as travestis levam o vestir, o falar e o comportar-se aos extremos da sensualidade, informando visualmente aos possíveis contratantes a possibilidade de satisfação no intercurso sexual.

Já para aquelas que não se enquadram num padrão estético sexualmente desejável, seja pelo pouco investimento econômico no corpo ou mesmo em função de um estado de saúde debilitado, a obtenção de renda por meio da prostituição se torna precária.

${ }^{5}$ As duas últimas interlocutoras preferiram não fornecer informações sobre a idade. 
Marisa (36 anos) é um exemplo etnográfico dessa realidade. Com um corpo magro e masculinizado, ela reclamava da dificuldade em efetivar algum programa na Trav. Antônio Baena; todavia, essa travesti ainda resiste em deixar a vida na pista ${ }^{6}$.

Como se não bastasse ter uma plástica pouco feminina, Marisa traz no corpo grande quantidade de cicatrizes, especialmente nos braços e antebraços. Conforme explicado pela interlocutora, tais marcas resultaram de confrontos físicos com clientes e com outros travestis, sendo que parte delas corresponde a cortes provocados por lâminas. $\mathrm{Na}$ foto ao lado, vê-se um registro de parte dessas cicatrizes, com destaque para a marca quelóide no alto do cotovelo esquerdo de Marisa.

As cicatrizes que Marisa e outras travestis como Débora, Suelma e Katriely trazem em seus corpos são sinais que comunicam um quadro de violência que permeia o cotidiano de quem vive da prostituição nas ruas de Belém. Nos espaços apropriados por esse segmento social, a violência se manifesta sob diferentes formas e envolve indivíduos distintos.

Tal como verificado por Silva (2007) no bairro da Lapa, na cidade do Rio de Janeiro, as travestis comunicam à sociedade a imagem de sujeitos perigosos. Isso se construiu ao recorrerem ao uso da força física para impor sua presença no espaço público, pois entre os anos de 1950 e 1960 elas eram agredidas " [...] se ousavam sair às ruas. Eram presos [as] por atentado ao pudor. Viviam espantados [as] e amedrontados [as] [...]" (SILVA, 2007, p. 65). No processo de passagem do gueto para as ruas, precisaram aprender a enfrentar aqueles que ofereciam perigo, não sendo raro utilizarem lâminas cortantes para intimidar os agressores.

\footnotetext{
${ }^{6} \mathrm{O}$ termo pista é um designativo dos (as) profissionais do sexo para fazer referência a qualquer via pública na qual se pratica a prostituição, seja uma avenida, travessa, rua, alameda ou rodovia (FERREIRA, 2003a).
}

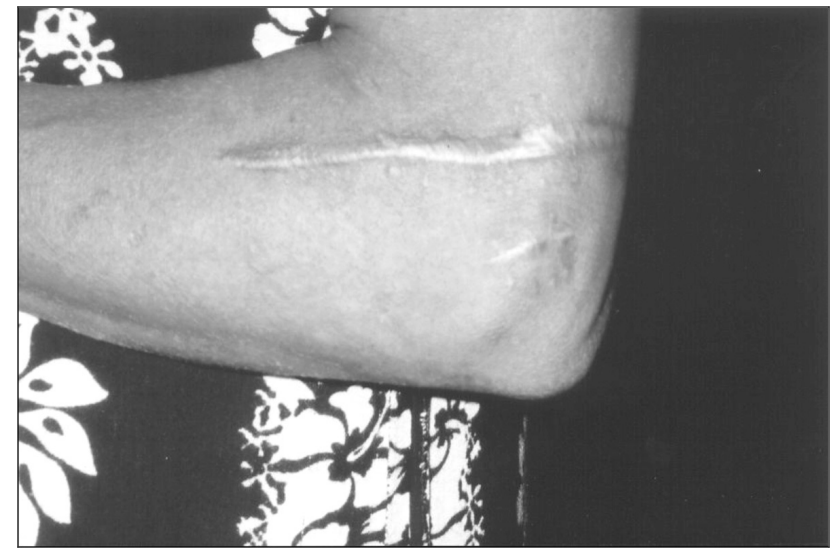

FOTO 1

A enorme cicatriz de Marisa é um sinal da violência presente nos territórios de prostituição de travestis em Belém ${ }^{7}$.

Foto: Ligia Simonian, 2002.

Em Belém, os moradores dos territórios de prostituição manifestaram o medo que sentem à medida que as travestis chegam ao anoitecer para ocupar as vias públicas transversais ao longo da Av. Almirante Barroso e da Av. Assis de Vasconcelos. João (61 anos) relata como precisou mudar de hábito para evitar problemas com as travestis que se prostituem na Trav. Antônio Baena:

Sempre foi o meu costume sentar na porta pra pegar vento, mas dentro desse horário [entre sete e oito horas da noite]. Depois dele você não pode sair na rua. Eles começam a chegar, vão pra ali [aponta para uma árvore num canto escuro a alguns metros de sua casa] e começam a mudar de roupa ali mesmo. Aí tu fica olhando sem poder fazer nada, porque se tu for reclamar eles vêm com as maiores agressões: - Eu não tô mudando a roupa aí na tua casa! E você tem que engolir [...] (Entrevista, 2002).

Nesses territórios, também é comum aos moradores e passantes presenciar brigas entre travestis e clientes ${ }^{8}$

\footnotetext{
O material fotográfico utilizado no trabalho foi produzido pela professora doutora Ligia T. Simonian (NAEA/UFPA), que orientou a dissertação e cedeu gentilmente as fotografias para este autor, o que nesta oportunidade agradeço.
} 
e mesmo entre outras travestis. No primeiro caso, a tensão se instala quando o acordo do programa é desrespeitado por qualquer uma das partes; no segundo, a disputa por clientes pode motivar a luta corporal.

De fato, parte dos moradores e passantes já assimilou que - embora de forma generalizante e preconceituosa - as travestis oferecem perigo. Nos territórios de prostituição em Belém, os moradores relataram várias situações em que presenciaram assaltos cometidos por essas profissionais do sexo. Amaral (48 anos; entrevista, 2002), morador da Rua Manoel Barata, e Antônio (33 anos; entrevista, 2002), que trabalha como vigilante num prédio privado na Assis de Vasconcelos, comentaram que são comuns os casos em que os clientes são assaltados pelas travestis. Em outro território de prostituição, na Av. Almirante Barroso, Mercedes (25 anos; entrevista, 2002), moradora da Tv. Antônio Baena, não esquece o dia em que assistiu o assalto a uma vizinha na entrada do edifício. Desde então, Mercedes evita sair à rua quando as travestis começam a chegar para batalhar.

O hábito de trocarem de roupa nos cantos escuros das vias públicas, as brigas e os assaltos são aspectos comumente denunciados pelos moradores dessas "áreas de obsolescência" (SOUZA, 1995, p.87). Todavia, as denúncias são feitas em sigilo, uma vez que eles temem possíveis represálias. João (entrevista, 2002) diz que as travestis chegam a intimidar aqueles que suspeitam serem seus delatores, ora de forma verbal, ora quebrando os vidros das janelas e/ou da porta da residência dos denunciantes a pedradas. Conforme declaração da delegada Aline Holanda (entrevista, 2003), da Seccional de São Brás, situada

\footnotetext{
${ }^{8}$ Recentemente o caderno policial do jornal Diário do Pará publicou a morte de J.G.S. (16 anos), travesti que se prostituía no território da Av. Almirante Barroso, no Marco, assinada por um cliente que dirigia um Celta verde (ATIRADORES, 2009). Dada a dificuldade para uma estatística oficial de homicídios envolvendo travestis como vítimas, os jornais impressos e online servem como importante fonte de informação para organizações não-governamentais produzirem suas próprias estatísticas sobre crimes contra homossexuais, tal como faz anualmente o Grupo Gay da Bahia (GGB), em Salvador.
}

próximo ao ponto de prostituição de travestis da Tv. Antonio Baena, atualmente o recolhimento desses sujeitos só ocorre nas situações de crimes de maior potencial ofensivo.

Entre esses, a delegada cita o furto e as agressões físicas eventualmente denunciadas pelos moradores ou pelos clientes, sendo que os últimos geralmente alegam tê-las contratado acreditando tratar-se de mulheres ${ }^{9}$. Então é lavrado um termo circunstanciado de ocorrência (TCO). As acusadas são liberadas em seguida para aguardar o pronunciamento do Juizado Especial, o qual pode determinar o pagamento de multa ou a prestação de serviços à comunidade.

Nos casos de atos obscenos denunciados pelos moradores dos territórios de prostituição, o procedimento policial tem sido orientado no sentido da advertência verbal. Porém, paralelo a esse controle, persiste o sexo compulsório e gratuito com os "homens da lei", a quem Raissa (entrevista, 2002) considera "[...] mais safados que os próprios bandidos e que os travestis, à medida que eles querem que a gente transe com eles de graça pra não ir presa [...]”. Há que se ressaltar que essa é uma realidade registrada em vários trabalhos antropológicos sobre esse segmento homossexual, tal como observaram Silva (2007) e Oliveira (1994).

Marginais, criminosas, vergonhosas, obscenas, desocupadas, inferiores. Desqualificações dessa ordem são projetadas pela sociedade maior sobre as travestis, notadamente por serem homossexuais e viverem da prostituição nas ruas. De fato os corpos das travestis parecem constituir a fonte de todo o estigma atribuído a elas, pois sua morfologia

\footnotetext{
9 Sobre esses "possíveis equívocos" a mídia tem veiculado com frequência situações nas quais estão envolvidas personalidades do meio artístico ou esportivo, a exemplo dos atores Rômulo Arantes Neto, Lui Mendes e Gabriel Nunes, e do jogador de futebol Ronaldo, cuja imagem pública ficou associada a encontros sexuais com travestis contatados em "pontos" de prostituição (RÔMULO, 2008; RONALDO, 2008; MAGALHÃES, 2007). Aliás, Andréia Albertini (22 anos), protagonista do escândalo sexual envolvendo o jogador Ronaldo reapareceu na mídia, mas tendo como foco da notícia o falecimento supostamente atribuído às complicações advindas da infecção por HIV (MORRE, 2009).
} 
semelhante à da mulher é o elemento mais visível do desvio que cometeram ao violar o sistema de gênero. É a partir dessa diferença tão evidente que os indivíduos que se consideram "normais" passam a atribuir todo tipo de defeitos a eles para (re) afirmarem sua "normalidade".

M.T.S. (45 anos; dona de casa), moradora da Tv. Antonio Baena, tem um entendimento sobre as travestis emblemático nesse sentido:

Pra mim o travesti é uma pessoa que se transforma; que não aceita o que ele é. Eu acho que é um tipo de doença [grifo meu], né? A mulher sim, se prostitui por necessidade, mas o travesti eu acho que é porque é uma doença. Graças a Deus não tem nenhum na minha família. Eu não quero nem pensar nisso (Entrevista, 2002).

Como a interlocutora deixa transparecer em suas palavras, os sinais sociocomportamentais dos corpos das travestis são lidos como sintomas de uma doença, o que parece corroborar o pensamento de cientistas que procuram explicar as diferenças afetivas e sexuais com base na genética (PEREIRA, 1994; BENITES, 1996; CARNEIRO, 2002), alimentando uma perspectiva de cura.

Ao considerar essa carga semântica pejorativa em decorrência do estigma, observa-se também que os efeitos deste podem ser estendidos à autoestima das entrevistadas. Sobre essa questão, Bruns e Marque (2002) argumentam que a ideologia da inferioridade que a sociedade maior constrói para explicar o indivíduo estigmatizado e desviante como "diferente" acaba sendo introjetada na psique, produzindo assim uma espécie de complexo que o faz sentir-se incapacitado para realizar as mesmas coisas que os "normais" conseguem fazer. Logo, quando Camila afirma "Eu sou é prostituta mesmo!" (entrevista, 2002), ela demonstra a conformação com sua condição social e econômica, como se não houvesse alternativa de superá-la por ser travesti.
Essa baixa estima pode indicar também a falta de projetos (VELHO, 1999) para quando chegar o momento em que a idade não lhes permitirá mais oferecer serviços sexuais remunerados. E quando esses projetos são vagamente elaborados, limitam-se à busca de um ideal de beleza a ser alcançado pelo uso de substâncias nocivas ao organismo, as quais certamente afetam a expectativa de vida. Destarte, a preocupação com a sobrevivência imediata nas ruas através do corpo parece sobrepor-se ao fato de que a prostituição tem um "tempo certo" para ser praticada, encontrando seu limite no avanço progressivo e ininterrupto da idade cronológica. Nessa fase da vida, seus corpos comunicam menos sensualidade e beleza, embora os preconceitos quanto a um modo de ser e de viver diferenciado persistam com a mesma intensidade no contexto de uma sociedade de domínio heterossexual.

\section{À GUISA DE CONCLUSÃO}

A interdisciplinaridade da ciência da informação viabiliza que seu objeto de estudo possa ser analisado sob os mais diferentes aspectos, além daqueles de ordem tecnológica e técnica que saturam a literatura especializada, inclusive no Brasil. Um olhar na perspectiva de outras disciplinas, como a antropologia, por exemplo, permite abordar a informação numa dimensão cultural e social que ainda precisa ser ampliada, precipuamente no que se refere aos problemas que afetam as sociedades contemporâneas em suas microestruturas.

No caso particular das travestis, é de chamar a atenção que num mundo em que se produzem e disseminam informações com muito mais facilidades, o preconceito e a intolerância ainda se impõem como barreiras ao respeito às diferenças, inclusive na abertura de outras oportunidades para esse segmento na vida em sociedade. Durante o trabalho de campo, em nenhum momento se verificou entre os indivíduos não travestis entrevistados qualquer referência que as valorizasse enquanto cidadãs. A partir da análise realizada sobre esse segmento 
social em Belém, fica evidente que a desinformação parece justapor-se ao preconceito, especialmente se este último for tido como todo julgamento a priori, produzido num contexto de ausência de informações exatas e confiáveis, resultando em leituras superficiais e aparentes dos indivíduos considerados "diferentes".

Entretanto, ao se pensar no entendimento goffmaniano sobre a informação social, as travestis em sua ambiguidade de gênero são interpretadas de forma sociodesvalorizada, ou na ótica dos clientes, como objeto sexual com o qual preferem interagir na clandestinidade para evitar a contaminação pelo estigma e, assim, preservar a masculinidade. De todo modo, ainda que se movimentando em um cenário permeado por dificuldades, as travestis resistem em sua leitura particular do sistema sexo/gênero.

Numa perspectiva teórica e metodológica, o exercício de observar um grupo específico de sujeitos que se encontram inseridos no contexto dinâmico e heterogêneo de uma cidade amazônica, mas sob a ótica informacional, permitiu analisar a informação para além de um conjunto semanticamente estruturado de dados comunicados por circuitos computacionais, tal como presume a ideia de uma sociedade tecnológica conectada em rede. Assim, a intersecção entre a antropologia e a ciência da informação se mostra capaz de produzir entendimentos mais complexos sobre a informação enquanto objeto de investigação e análise interdisciplinar, sobretudo no sentido de compreender como ela está disseminada no cotidiano, reflete-se e afeta a vida dos indivíduos inseridos em sociedades complexas como a brasileira.

Artigo submetido em 15/12/2008 e aceito em 30/07/2009.

\section{REFERÊNCIAS}

ARAÚJO, Carlos Alberto Ávila. A Ciência da Informação como ciência social. Ciência da Informação, Brasília, v. 32, n. 3, p. 21-27, set./ dez. 2003.

ARAÚJO, Elany Alvarenga de. Informação, sociedade e cidadania: práticas informacionais de Organizações Não-Governamentais ONGs brasileiras. Ciência da Informação, Brasília, v. 29, n. 2, p. 155-167, maio/ago. 1999.

ATIRADORES matam travesti na Almirante. Diário do Pará, Belém, 23 jun. 2009. Polícia, p. 5.

BENEDETTI, Marcos Renato. Hormonizada! Reflexões sobre o uso de hormônios e tecnologia do gênero entre travestis. In: FÁBREGASMARTÍNEZ, Ana Isabel; BENEDETTI, Marcos Renato (Org.). $\mathrm{Na}$ batalha: identidade, sexualidade e poder no universo da prostituição. Porto Alegre: Dacasa, 2000. p. 47-62.

Toda feita: o corpo e o gênero dos travestis. Rio de Janeiro: Garamond, 2005. (Gênero e sexualidade; Homossexualidade e Cultura).

BENITES, Maria José de O. Fantasias sexuais dos travestis. Revista Brasileira de Sexualidade Humana, São Paulo, v. 7, n. 1, p. 26-43.1996.

BRUNS, Maria A.; MARQUE, Cristiane R. Homossexualidade: depoimentos de homens. DST - Jornal Brasileiro de Doenças Sexualmente Transmissíveis, v. 14, n. 2, p. 5-11, 2002.

CARNEIRO gay pode ajudar estudos sobre homossexualidade humana. O Liberal, 10 nov. 2002. Atualidades, p. 11.

FERREIRA, Rubens da S. As "bonecas" da pista no horizonte da cidadania: uma jornada no cotidiano travesti. 2003a, 153 f. Dissertação (Mestrado em Planejamento do Desenvolvimento) - Núcleo de Altos Estudos Amazônicos. Universidade Federal do Pará, 2003a.

A sociedade da informação no Brasil: um ensaio sobre os desafios do Estado. Ciência da Informação, Brasília, v. 32, n. 1, p. 36-41, jan./abr. 2003b.

FREIRE, Isa Maria. A responsabilidade social da ciência da informação e/ ou o olhar da consciência possivel sobre o campo científico. 2001. Tese (Doutorado em Ciência da Informação) - Instituto Brasileiro de Informação Científica e Tecnológica, Universidade Federal do Rio de Janeiro, 2001.

GIRÃO, Adriana Freire; LIMA, Fábia Pereira. Nem azul, nem rosa: uma leitura de marketing na prostituição travesti. Pontifícia Universidade Católica de Minas Gerais, 1999. Disponível < http://www.fafich.ufmg. $\mathrm{br} / \sim$ larp/semanarp/adrianagirao.htm $>$. Capturado $<17.02 .2002>$.

GOFFMAN, Erving. A representação do eu na vida quotidiana. 13. ed. Petrópolis: Vozes, 2005. (Antropologia; 8).

Estigma: notas sobre a manipulação da identidade deteriorada. 3. ed. Rio de Janeiro: Zahar, 2008. (Antropologia Social).

KULICK, Don. Travesti: sex, gender and culture among Brazilian transgendered prostitutes. Chicago: The University of Chicago Press, 1998.

MAGALHÃES, William. Ator da Record é acusado de bater em travesti. A Capa. Disponível em: < http://www.acapa.com.br/site/ noticia.asp? codigo $=2595>$. Acesso em: 20 out. 2007. 
MALINOWSKI, Bronislaw. A diary in the strict sense of the term. Stanford: Stanford University Press, 1989.

MATTOS, Fernando Augusto M. Inclusão digital e desenvolvimento econômico na construção da sociedade da informação no Brasil. DataGramaZero - Revista de Ciência da Informação, v.7, n.3, jun. 2006. Artigo 03. Disponível em: <http://www.dgz.org.br/jun06/ Art 03.htm>. Acesso: 21 abr. 2008.

MAUSS, Marcel. Sociologia e antropologia. São Paulo: Cosac Naify, 2003.

MORRE travesti de escândalo com Ronaldo. Revista Época. Disponível em: <http://revistaepoca.globo.com/Revista/ Epoca/0, EMI81791-15228,00-MORRE+TRAVESTI+DE+ ESCANDALO+COM+RONALDO.html>. Acesso em: 10 jul. 2009.

MOTT, Luiz. A cena gay de Salvador em tempos de AIDS. Salvador: Grupo Gay da Bahia, 2000.

OLIVEIRA, Neuza Maria de. Damas de paus: o jogo aberto dos travestis no espelho da mulher. Salvador: Centro Editorial e Didático da UFBA, 1994.

OLIVEIRA, Roberto Cardoso de. O trabalho do antropólogo: olhar, ouvir, escrever. Revista de Antropologia, São Paulo, v. 39, n. 1, p. 13-37. 1996.

PEREIRA, Carlos Alberto Messeder. O direito de curar: homossexualidade e medicina legal no Brasil dos anos 30. In: HERSHMANN, Michel M.; PEREIRA, Carlos Alberto Messeder (Org.). A invenção do Brasil moderno: medicina, educação e engenharia nos anos 20-30. Rio de Janeiro: Rocco, 1994. p. 88-129.

PINHEIRO, Lena Vânia Ribeiro; LOUREIRO, José Mauro Matheus. Traçados e limites da Ciência da Informação. Ciência da Informação, Brasília, v. 24, n. 1, 1995. Disponível em: <www.ibict.br/cionline/ viewarticle.php?id=576>. Acesso em: 12 jan. 2007.
QUEIROZ, João. Comunicação animal: problemas e métodos. Revista eletrônica de jornalismo científico Com Ciência, n. 80. 2006. Disponível em: $<\underline{\text { http: } / / \text { www.comciencia.br/comciencia/?section }=8 \& \text { edicao }=17 \&}$ $\underline{\mathrm{id}=174}>$. Acesso em: 13 set. 2006.

RÔMULO Arantes, capa da revista gay Junior diz que travestis são “insatisfeitas, muito infeliz". A Capa, 15 maio 2008. Disponível em: $<$ http://acapa.com.br/site/noticia.asp? codigo $=4515 \& \mathrm{R} \% \mathrm{~F} 4$ mulo + Arantes, + capa + da + revista + gay + Junior, + diz + que + travestis $+\mathrm{s} \%$ E3o+"insatisfeitas, +muito+infeliz"> . Acesso: 16 maio 2008.

RONALDO fenômeno é acusado de não pagar programa a travesti. O Globo, 28 abr. 2008. Disponível em: <http://oglobo.globo.com/ rio/mat/2008/04/28/ronaldo fenomeno acusado de nao pagar programa_travesti-427106491.asp>. Acesso: 6 maio 2008.

SILVA, Hélio R. S. Travestis: entre o espelho e a rua. Rio de Janeiro: Rocco, 2007. (Gênero Plural).

SIMONIAN, Ligia T. L. Políticas públicas, desenvolvimento sustentável e recursos naturais em áreas de reserva na Amazônia Brasileira. In: COELHO, Maria Célia N.; SIMONIAN, Ligia T.; FENZEL, Norbert (Org.). Estado e políticas públicas na Amaz̧ônia: gestão de recursos naturais. Belém: Cejup, 2000. p. 9-53. (Série Estado e Gestão Pública, 1).

SOUSA, Paulo de Tarso Costa de. Capital Social e Gestão do Conhecimento: união responsável socialmente. DataGramaZero Revista de Ciência da Informação, v.7, n. 6, dez. 2006. Artigo 02. Disponível em: <http://www.dgz.org.br/dez06/Art 02.htm>. Acesso: 18 abr. 2008.

SOUZA, Marcelo José L. O território: sobre espaço e poder, autonomia e desenvolvimento. In: CASTRO, Ina Elias de; GOMES; Paulo César da Costa; CORRÊA, Roberto Lobato (Org.). Geografia: conceitos e temas. Rio de Janeiro: Bertrand Brasil, 1995. p. 77-116.

VELHO, Gilberto. Projeto e metamorfose: antropologia das sociedades complexas. 2. ed. Rio de Janeiro: Jorge Zahar, 1999. 